\title{
Isolation, identification, and study of the genetic diversity between three entomopathogenic nematodes belonging to Heterorhabditis sp. using ISSR technique
}

\author{
Etr H. K. Khashaba* (D) and Amany M. A. Abd El Azim
}

\begin{abstract}
Background: Entomopathogenic nematodes (EPNs) are widely used in biological control for soil-dwelling stages of many insect pests that are characterized by their safety to most non-target organisms and to the environment.

Results: The objectives of the present study were isolation of EPNs from agricultural soil in Egypt for further use in biological control programs and study the genetic variation among them using the molecular marker inter-simple sequence repeats (ISSR). Three out of 25 soil samples collected from fields cultivated with strawberry, tangerine, and pumpkin were positive for the presence of EPNs, using the Galleria baiting technique. Sequencing of the internal transcribed spacer (ITS) region indicated that the isolates obtained belong to Heterorhabditis sp. The ITS sequences were submitted to the National Center for Biotechnology Information (NCBI) and registered under accession nos. MH553165, MH553168, and MH553169. Six ISSR primers were used. The numbers of polymorphic bands were 42 out of 56, and the polymorphism percentage was 75\%. The highest number of bands was 12 bands generated by primer ISSR8 followed by UBC-809 (11 bands) while recorded the lowest band number (4 bands), the percentage of polymorphism ranged from 40\% (ISSR1) to 100\% (ISSR6).

Conclusion: ISSR marker can be considered a good marker to study genetic diversity and detecting the genetic polymorphism among the nematodes species.
\end{abstract}

Keywords: Entomopathogenic nematodes, DNA sequences, Heterorhabditis sp., ISSR, Genetic diversity

\section{Background}

Entomopathogenic nematodes (EPN) belonging to the families Steinernematidae and Heterorhabditidae are obligate parasites of soil-inhabiting insects and have a great potential as biological control agents of many insect pests (Gaugler 2002). However, interest in EPN has been increased in recent years, as hundreds of laboratories worldwide conducting research on these beneficial organisms (Khashaba et al. 2020).

The non-feeding infective juvenile (IJ) stage kills the insects at different stages of larvae, pupae, and adults

\footnotetext{
*Correspondence: ater_hk@yahoo.com

Plant Protection Research Institute, Agriculture Research Center, Giza, Egypt
}

depending upon the species of nematodes and insects. It penetrates into the insect's body usually through natural body openings or areas of thin cuticle when it reaches the hemocoel of the host with the help of their own associated bacterial symbionts causing death within 24-72 h (Laznik et al. 2011). The bacterium serves as a food source for the nematode and is required for the nematode.

DNA markers are numerous and widespread throughout the genome (Agarwal et al. 2008). Molecular markers assess to diagnose and identify the evolutionary relationships of EPN. Among these markers, the ribosomal genes include the $18 \mathrm{~S}$ rRNA gene, the internal transcribed spacers (ITS1 and ITS2), and the 5.8S and the 28S rRNA 
genes, which make them ideal for phylogenetic studies at species and population levels (Mehle and Trdan 2012).

Amplified fragment length polymorphism (AFLP), simple sequence repeats (SSR), inter-simple sequence repeats (ISSR), and sequence-related amplified polymorphism (SRAP) are highly polymorphic and constant and have been widely employed in molecular taxonomy, phylogeny, and genetic mapping (Zhao et al. 2009).

The inter-simple sequence repeats (ISSR) technique has been developed to study the genetic diversity and fingerprinting, mapping, and gene tagging among the population of the same and closely related species (Lax et al. 2007). ISSR primers are rapid, sensitive, and have higher annealing temperatures, which results in greater band reproducibility (Culley and Wolfe 2001). They also reveal a high genetic variability.

The present study aimed to isolate and identify local EPN isolates, belonging to the genus Heterorhabditis sp., collected from the eastern Governorate of Egypt and to reveal the genetic variability among them based on ISSR markers.

\section{Methods}

Soil sampling and isolation of nematodes

In 2017, soil samples were collected from different newly reclaimed agricultural areas cultivated with strawberry, pumpkin, and tangerine, from Ismailia with district coordinates N 30 $34^{\prime} 28.42^{\prime \prime}$, E $32^{\circ} 13^{\prime} 55.66^{\prime \prime}$ for isolate ERSAG1 and N $30^{\circ} 37^{\prime} 16.77^{\prime \prime}$, E $32^{\circ} 15^{\prime} 0.55^{\prime \prime}$ for isolate ERSAG3 and at Port Said Governorate route with district coordinates N 30 54' 29.85", E $32^{\circ} 10^{\prime} 13.98^{\prime \prime}$ for isolate ERSAG4.

Each sample contained 4 subsamples $20 \mathrm{~cm}$ deep, randomly taken. The subsamples were combined to form a single assembly sample. All soil samples were brought to the laboratory and stored at $20{ }^{\circ} \mathrm{C}$ and were homogenized before the extraction of EPNs.

Nematodes were recovered from the soil samples by using the insect-baiting technique (Bedding and Akhurst 1975). Each sample was baited by 10 last instar larvae of Galleria mellonella L. The boxes were inverted and kept in the dark at $25 \pm 2{ }^{\circ} \mathrm{C}$ and $75 \pm 5 \mathrm{RH}$. During 7 days as a holding period, the samples were checked for the presence of dead insects. The dead larvae were transferred individually to modified White traps (Kaya and Stock 1997).

Nematodes were harvested within the first week of emergence and used to inoculate G. mellonella larvae. To confirm their pathogenicity to insects, the infective juveniles (IJs) were transferred onto moist filter paper in Petri dishes where living G. mellonella larvae were added. The new generation of IJs was collected in a beaker and rinsed twice with sterile distilled water and stored at $16{ }^{\circ} \mathrm{C}$ as described by Kaya and Stock (1997).

\section{Molecular characterization of the isolates}

Molecular characterization of the isolates was performed by analysis of the ITS rDNA sequences. DNA was extracted from EPN according to the method described by Kary et al. (2009) as follows.

The nematodes were crushed approximately 2000 IJs in $20 \mu \mathrm{l} 1 \times$ PCR buffer and transferred to a precooled sterilized $1.5 \mathrm{ml}$ tube containing $20 \mu \mathrm{l}$ of the same buffer. The tube was incubated at $-70{ }^{\circ} \mathrm{C}$ for $15 \mathrm{~min}$ and thawed at $60^{\circ} \mathrm{C}$ then inoculated with $5 \mu \mathrm{l} \mathrm{of} 60 \mu \mathrm{g} / \mathrm{ml}$ proteinase $\mathrm{K}$. The tube was incubated at $65^{\circ} \mathrm{C}$ for $2 \mathrm{~h}$ and then heated at $95^{\circ} \mathrm{C}$ for $15 \mathrm{~min}$. After centrifugation at $16.000 \mathrm{rpm}$ for 15 min, the supernatant containing nematode DNA was collected and stored at $-70^{\circ} \mathrm{C}$ until use. The quality and quantity of DNA were determined using $1 \%$ agarose gel electrophoresis and spectrophotometer.

The ITS region of the nematode rDNA was amplified by PCR in a $20 \mu \mathrm{l}$ reaction mix containing $2 \mu \mathrm{l}$ of the DNA suspension, $2 \mu$ of 10X PCR buffer, $2 \mu \mathrm{l}$ of $\mathrm{MgCl}_{2}(25 \mathrm{mM}), 1$ $\mu \mathrm{l}$ of dNTP mixture (10 mM of each dNTP), $0.5 \mathrm{U}$ of Taq DNA polymerase and $10.5 \mu \mathrm{l}$ of dd $\mathrm{H}_{2} \mathrm{O}, 1 \mu \mathrm{l}$ of the forward primer TW81: 5-GTTTCCGTAGGTGAACCTGC-3', and $1 \mu \mathrm{L}$ of the reverse primer AB28:5'-ATATGCT TAAGTTCAGCGGGT3 (Joyce et al. 1994).

For the ITS rDNA region, the PCR cycling conditions included initial denaturation at $94{ }^{\circ} \mathrm{C}$ for $5 \mathrm{~min}$, followed by 30 cycles of $94{ }^{\circ} \mathrm{C}$ for $1 \mathrm{~min}, 64^{\circ} \mathrm{C}$ for $1 \mathrm{~min}$, and $72^{\circ} \mathrm{C}$ for $1 \mathrm{~min}$, followed by a final extension at $72^{\circ} \mathrm{C}$ for $5 \mathrm{~min}$. Subsequently, the product was loaded on a $2 \%$ agarose gel. The PCR products were purified using the Wizard $^{\circ}$ SV Gel and PCR Clean-Up System Kit (Promega) following the manufacturer's instructions. PCR products were sequenced using sequence-specific primers with a BigDye Terminator Cycle Sequencing Ready Reaction Kit (PE Applied Biosystem, USA) and carried out on ABI PRISM 310 Genetic Analyzer (PE Applied Biosystems, USA) in both directions by the Macrogen Inc. service, South Korea.

The identity of approximately 700 bp sequences was confirmed by a BLAST (Basic Local Alignment Search Tool) search at NCBI (National Center for Biotechnology Information). The obtained sequences of Heterorhabditis isolates were compared by sequences of the Heterorhabditis sp. and located at the NCBI database with the accession numbers listed in Table 1.

\section{Phylogenetic analysis}

A phylogenetic tree was created on the phylogeny.fr platform: http://www.phylogeny.fr/ (Dereeper et al. 2008). ITS sequences were aligned using the Muscle program. The phylogeny was reconstructed, using the maximum likelihood method (PhyML program), and reliability for the internal branch was assessed, using the 
Table 1 Gene bank accession numbers for ITS1-5.8S-ITS2 sequences and the result of their BLAST against the Nucleotide collection (nt) database of the NCBI website

\begin{tabular}{llll}
\hline Isolate & Accession no. & Species & Habitat \\
\hline ERSAG1 & MH553165 & Heterorhabditis sp. & Pumpkin field \\
ERSAG3 & MH553168 & Heterorhabditis sp. & Strawberry field \\
ERSAG4 & MH553169 & Heterorhabditis sp. & Tangerine field \\
\hline
\end{tabular}

Bootstrapping procedure (100). The tree rendering was performed using TreeDyn software.

\section{ISSR analysis}

\section{$P C R$ analysis}

One micromolar of 5 arbitrary 10-mer primers (Operon Technology, Inc., Alameda, CA, USA) listed in Table 2 was used in the PCR reaction mixture, which was also containing 10 ng DNA, 0.5 units of Taq polymerase (Thermo Fisher Scientific), $200 \mu \mathrm{M}$ dNTPs, and 10-X Taq polymerase buffer (Thermo Fisher Scientific), and the total volume are adjusted to $20 \mu \mathrm{l}$. Biometra thermal cycler (2004 vers.1.12tp) was used for DNA amplification and programmed as follows: $94^{\circ} \mathrm{C}$ for $5 \mathrm{~min}$., followed by 40 cycles of $94^{\circ} \mathrm{C}$ for $1 \mathrm{~min}, 40^{\circ} \mathrm{C}$ for $1 \mathrm{~min}, 72^{\circ} \mathrm{C}$ for 1 min, and $72^{\circ} \mathrm{C}$ for $5 \mathrm{~min}$. The amplification products were analyzed by electrophoresis in 1.3\% agarose in TAE buffer, stained by ethidium bromide, and photographed under UV light.

\section{Results}

Twenty-five soil samples were collected from the fields in the governorates of Ismailia and Port Said. Three Heterorhabditis isolates were obtained (12\%) according to the morphological symptoms of dead larvae (brown/ black in color). The positive soil samples were classified as sandy clay loam with a climate temperature of $25^{\circ} \mathrm{C}$.

\section{Molecular characterization}

For the purpose of identifying the 3 isolates of EPNs at the species level, PCR product of approximately 700800 bp containing ITS1-5.8S-ITS2 sequences was BLASTed against the nucleotide collection (nr/nt) database and compared to other described species and available in GenBank with accession no. listed in Table 1, as

Table 2 Names and sequences of ISSR primers used

\begin{tabular}{ll}
\hline Primer name & Sequence \\
\hline UBC-809 & 5' (AG)8G \\
UBC-810 & 5' (GA)8T \\
UBC-864 & 5' (ATG)6 \\
ISSR 6 & 5'ACTCAGCCAC3' \\
ISSR 8 & 5'AATCGGGCTG3' \\
ISSR 1 & 5'TGTCATCCCC3' \\
\hline
\end{tabular}

several studies on molecular markers showed that the $28 \mathrm{~S}$ and ITS regions from ribosomal DNA can be considered the best DNA regions to study phylogenetic relationships among EPN (Stock et al. 2001; Nguyen et al. 2007). Based on sequence homology, the 3 isolates ERSA G1, ERSAG3, ERSAG4 showed a 99\% similarity identical to that of Heterorhabditis spp. as shown in Table 1.

\section{Phylogenetic analysis based on ITS sequences}

Nematodes isolated from the positive samples were identified based on ITS sequences compared with the EPN sequences from members of the "Heterorhabditis spp." group derived from NCBI, using BLAST as references. It classified the 3 new isolates in a clade with other isolates of Heterorhabditis sp. They were assembled using the Phylogeny.fr program and classified them in a clade with other isolates of the Heterorahabditis species available in the GenBank database (Fig. 1). The phylogenetic tree showed that the 3 isolated Heterorhabditis sp. and Heterorhabditis sp. WS1 (KP325085) from South Africa belong to the same clad. Also, the alignment of the ITS1 sequence from ERSAG1, ERSAG3, and ERSAG4 was distinguishable as shown in Fig. 2.

\section{Polymorphisms detected by ISSR markers}

Fifty-six bands sized from (100 to 2000) were generated by using 6 different primer pairs of ISSR marker, 42 bands were polymorphic, and the polymorphism percentage was $75 \%$. The highest number of bands were 12 bands that is generated by the ISSR8 primer followed by UBC-809 (11 bands) while UBC-864 recorded the lowest bands number (4 bands); the percentage of polymorphism ranged from 40\% (ISSR1) to 100\% (ISSR6) (Fig. 3 and Table 3).

\section{The relationship among the 3 Heterorhabditis sp. isolates based on ISSR primers}

Obtained data from ISSR primers was used to calculate the phylogenetic relationship among the 3 isolates. The cluster dendrogram showed 2 major clusters. The first one was divided into 2 branches: the first one had ERSA G3, and the second branch had ERSAG4. The second cluster had ERSAG1 (Fig. 4). The phylogenetic tree based on ISSR and the phylogenetic tree based on ITS

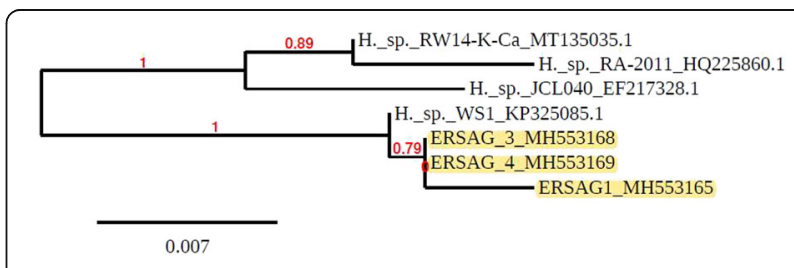

Fig. 1 Maximum likelihood ITS phylogenetic trees of Heterorhabditis species using ITS sequence. Based on nucleotide sequences of Heterorhabditis sp. (ERSAG1, ERSAG3, ERSAG4) and reference strains (alignment length $~ 700 \mathrm{bp}$ using phylo_ tree analysis) 


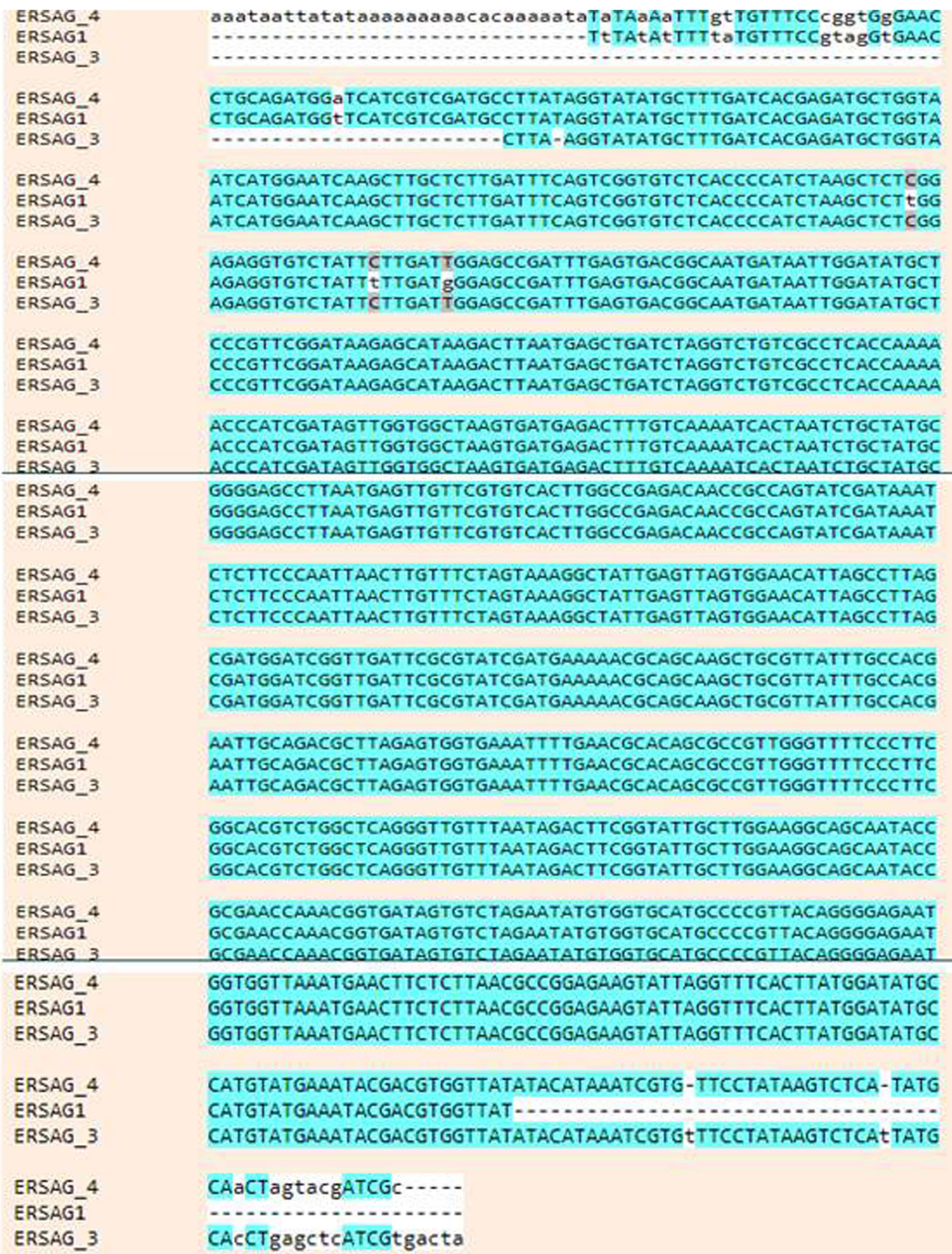
ACCCATCGATAGTTGGTGGCTAAGTGATGAGACTTTGTCAAAATCACTAATCTGCTATGC ACCCATCGATAGTIGGIGGCTAAGTGATGAGACTITGICAAAATCACTAATCTGCTATGC GGGGAGCCTTAATGAGTTGTTCGTGTCACTTGGCCGAGACAACCGCCAGTATCGATAAAT GGGGAGCCTTAATGAGTTGTTCGTGTCACTTGGCCGAGACAACCGCCAGTATCGATAAAT GGGGAGCCTTAATGAGTTGTTCGTGTCACTTGGCCGAGACAACCGCCAGTATCGATAAAT

CTCTTCCCAATTAACT TGTTTCTAGTAAAGGCTATTGAGTTAGTGGAACATTAGCCTTAG CTCTTCCCAATTAACT TGTTTCTAGTAAAGGCTATTGAGTTAGTGGAACATTAGCCTTAG CTCTTCCCAATTAACT TGTTTCTAGT AAAGGCTATTGAGTTAGTGGAACATTAGCCTTAG

CGATGGATCGGTTGATTCGCGTATCGATGAAAAACGCAGCAAGCTGCGTTATTTGCCACG CGATGGATCGGTTGATTCGCGTATCGATGAAAAACGCAGCAAGCTGCGTTATTTGCCACG CGATGGATCGGTTGATTCGCGTATCGATGAAAAACGCAGCAAGCTGCGTTATTTGCCACG

AATTGCAGACGCTTAGAGTGGTGAAATTTTGAACGCACAGCGCCGTTGGGTTTTCCCTTC AATTGCAGACGCTTAGAGTGGTGAAATTT TGAACGCACAGCGCCGTTGGGTTT TCCCTTC AATTGCAGACGCTTAGAGTGGTGAAATTT TGAACGCACAGCGCCGTTGGGTTTTCCCTTC

GGCACGTCTGGCTCAGGGTTGTTTAATAGACTTCGGTATTGCTTGGAAGGCAGCAATACC GGCACGTCTGGCTCAGGGTTGTTTAATAGACTTCGGTATTGCTTGGAAGGCAGCAATACC GGCACGTCTGGCTCAGGGTTGTTTAATAGACTTCGGTATTGCTTGGAAGGCAGCAATACC

GCGAACCAAACGGTGATAGTGTCTAGAATATGTGGTGCATGCCCCGTTACAGGGGAGAAT GCGAACCAAACGGTGATAGTGTCTAGAATATGTGGTGCATGCCCCGTTACAGGGGAGAAT GCGAACCAAACGGTGATAGTGTCTAGAATATGTGGGCATGCCCCGTTACAGGGGAGAAT GGTGGTTAAATGAACTTCTCTTAACGCCGGAGAAGTATTAGGTTTCACTTATGGATATGC GGTGGTTAAATGAACTTCTCTTAACGCCGGAGAAGTATTAGGTTTCACTTATGGATATGC GGTGGTTAAATGAACTTCTCTTAACGCCGGAGAAGTATTAGGTTTCACTTATGGATATGC

Fig. 2 Alignment of ITS1 sequences from Heterorhabditis sp. ERSAG1, ERSAG3, and ERSAG4. Identical positions are shadowed 


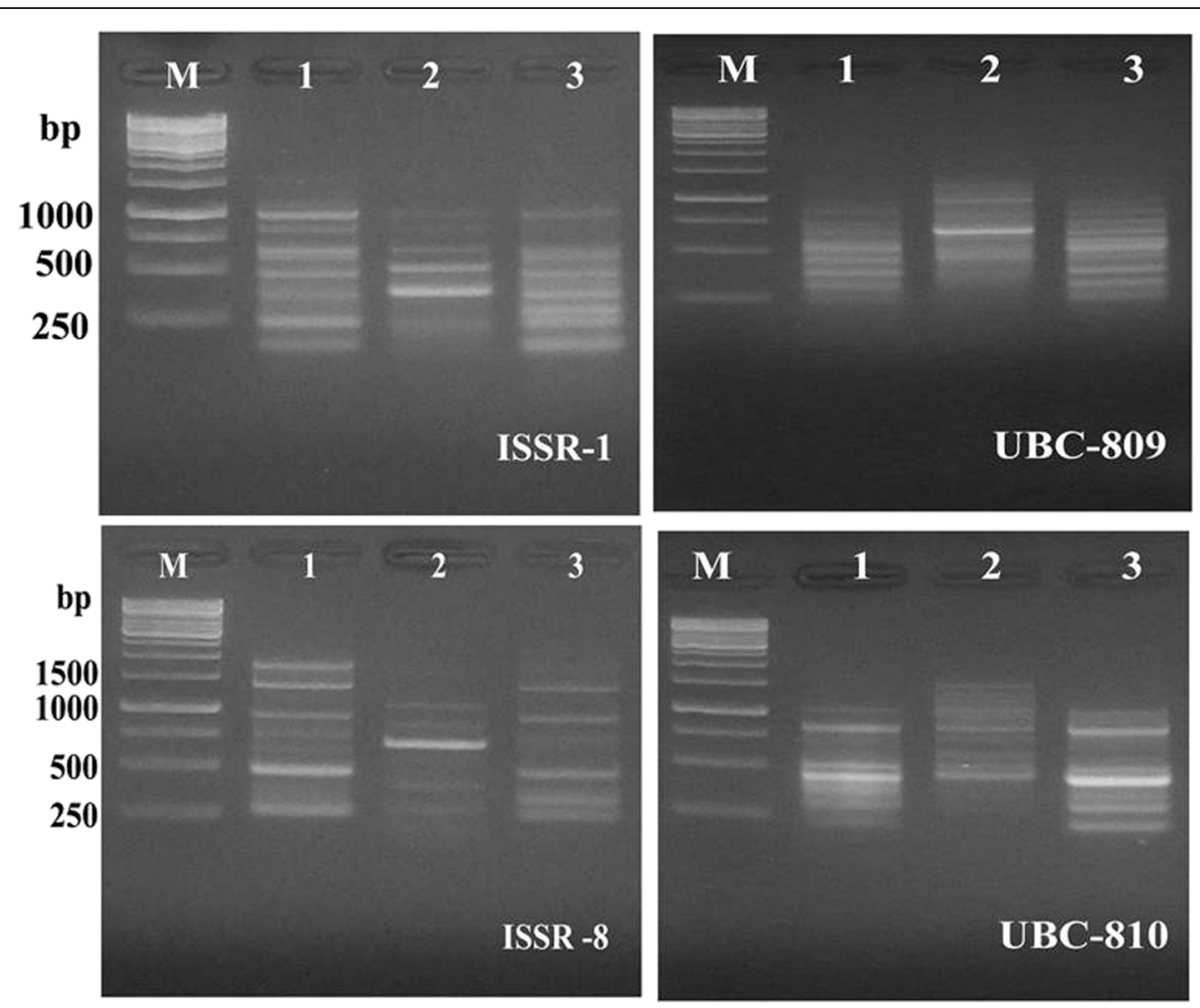

Fig. 3 Genetic polymorphism among the three isolates belongs to the family Heterorhabditis sp. as revealed by the ISSR analysis. M: 1 kbp plus DNA ladder; 1-3, the nematode isolates (1, ERSAG3; 2, ERSAG1; 3, ERSAG4)

harmonize with the data obtained by the sequence alignment that states the close relationship between ERSAG3 and ERSAG4.

\section{Discussion}

Accurate identification of EPNs has important collaboration in systematics and population genetics and has significant importance for the selection of species for future use in biological control programs. The molecular method is necessary to solve a variety of issues in EPN taxonomy.

As the present study was aimed to isolate and understand the occurrence of indigenous EPNs isolates in Egypt, positive soil samples were analyzed with additional information like temperature, altitude, and soil type. Although EPN were recovered at a rate of $12 \%$ of sampling sites in this study, the positive soil samples were classified as sandy clay loam. These results are similar to those reported by Valadas et al. (2013); Singh et al. (2015) and Khashaba et al. (2020) reported that most positive soil samples were sandy clay loam. The temperatures of all the collecting points were reported as $25{ }^{\circ} \mathrm{C}$ which agrees with Mejia-Torres and Sáenz (2013) who reported that Heterorhabditis sp. SL0708 exposed to temperatures between 20 and $30^{\circ} \mathrm{C}$ did not affect their viability over time, which was within the range established for other Heterorhabditidae.

Table 3 Total number of scorable bands, polymorphism percentage, and band size of ISSR markers obtained by 6 primers

\begin{tabular}{lllll}
\hline Primers & Total scorable bands & Polymorphic bands & Polymorphism & Band size range \\
\hline UBC-809 & 11 & 9 & $81.8 \%$ & $250-1000$ \\
UBC-810 & 10 & 6 & $60 \%$ & $100-1500$ \\
UBC-864 & 4 & 3 & $75 \%$ & $250-750$ \\
ISSR 6 & 9 & 9 & $100 \%$ & $400-2000$ \\
ISSR 8 & 12 & 11 & $91.6 \%$ & $250-1800$ \\
ISSR 1 & 10 & 4 & $40 \%$ & $100-1100$ \\
Total & 56 & 42 & $75 \%$ & \\
\hline
\end{tabular}




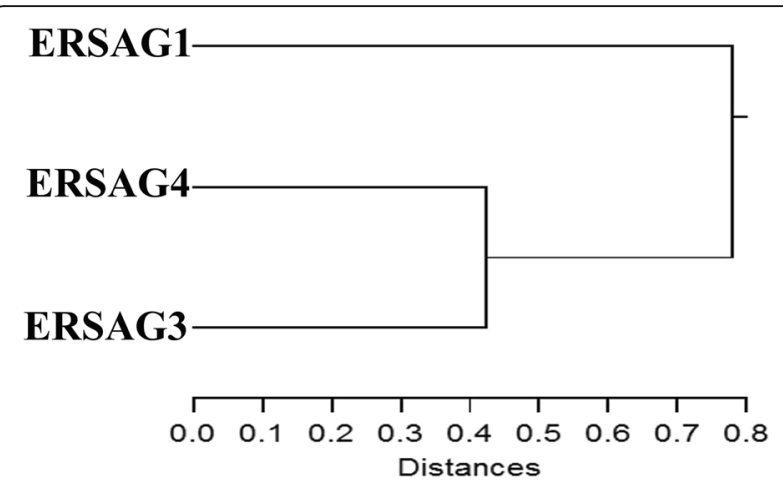

Fig. 4 Phylogenetic tree of the three Heterorhabditis sp. isolates based on ISSR markers

Based on sequence homology data, the 3 isolates were 99\% similarity identical to that of Heterorhabditis sp., according to Isaac et al. (2004) who claimed to avoid taxonomic inflation so considering the obtained isolates as members of the previously well-characterized species. The great geographical distances among the sites of occurrence for the "Heterorhabditis sp." nematodes (i.e., South Africa and Egypt) might be due to the phenomena called "latitudinal clades" which was previously described by Dolgin et al. (2008).

ISSR is a simple, quick method and highly polymorphic that combines most of the advantages of microsatellites (SSRs) and amplified fragment length polymorphism (AFLP) to the universality of random amplified polymorphic DNA (RAPD). ISSR markers are useful in studies on genetic diversity, phylogeny, gene tagging, genome mapping, and evolutionary biology (Reddy et al. 2002).

The percentage of polymorphism of using ISSR markers ranged from $40 \%$ (ISSR1) to $100 \%$ (ISSR6), and the polymorphism percentage was $75 \%$. This similarly agree with Nour El-Deen (2018) who studied the characterization of 3 isolates of EPNs Steinernema feltiae, Heterorhabditis bacteriophora, and Steinernema sp. using ISSR primers and assessed that the polymorphism percentage ranging from 0 to $100 \%$, and the polymorphism percentage for primers UBC-809, UBC-810, and UBC-864 was 100, 100, and 77.7\%, respectively. Also, Machkour-M'Rabet et al. (2009) affirmed that the ISSRPCR method is a promising method for intraspecific variation of tarantula spiders.

Based on the data obtained from the ISSR, phylogenetic tree based on ITS, there was a harmonization with the sequence alignment, which stated the close relationship between ERSAG3 and ERSAG4. Therefore, the ISSR molecular marker can be used to assign the genetic variability among the EPN species, which agrees with Nour El Deen (2018) who confirmed that the performance of the ISSR marker system to vent variation in the abundant microsatellite regions scattered, throughout the EPNs genome.

\section{Conclusion}

The present investigations identified 3 native EPN isolates from the Egyptian soil belonging to Heterorhabditis sp., which could be used in biological control and integrated pest management programs. The study revealed the genetic variability among them, using the ISSR marker, which was approved to be successful molecular markers for estimating genetic polymorphism and the genetic relationships among the EPNs. Further study will be carried out on the species identification of the 3 Heterorhabditis sp.

\section{Abbreviations}

ISSR: Inter-simple sequence repeats; ITS: Internal transcribed spacer; NCBI: National Center for Biotechnology Information

\section{Acknowledgements}

We would like to thank Prof. Dr. Gamal A. El Kady (Plant Protection Department, Faculty of Agriculture, Suez Canal University, Egypt) for helping in the critical reading of the manuscript.

\section{Authors' contributions}

E. H. K. K. participated in the experimental design and practical work and coordinated the manuscript writing. A.M.A.A. participated in the experimental design, practical work, and manuscript writing. All authors read and approved the final manuscript.

\section{Funding}

This research did not receive any specific grant from funding agencies in public, commercial, or not-for-profit sectors.

Availability of data and materials

All datasets are presented in the main manuscript.

\section{Declarations}

Ethics approval and consent to participate Not applicable

\section{Consent for publication}

Not applicable

\section{Competing interests}

The authors declare that they have no competing interests.

Received: 15 December 2020 Accepted: 26 April 2021

Published online: 13 May 2021

\section{References}

Agarwal M, Shrivastava N, Padh H (2008) Advances in molecular marker techniques and their applications in plant sciences. Plant Cell Rep. 27(4):617631. https://doi.org/10.1007/s00299-008-0507-z

Bedding RA, Akhurst RJ (1975) A simple technique for the detection of insect parasitic nematodes in soil. Nematologica. 21(1):109-110. https://doi.org/1 $0.1163 / 187529275 \times 00419$

Culley TM, Wolfe AD (2001) Population genetic structure of the cleistogamous plant species Viola pubescens Aiton (Violaceae), as indicated by allozyme and ISSR molecular markers. Heredity 86(5):545-556

Dereeper A, Guignon V, Blanc G, Audic S, Buffet S, Chevenet F, Dufayard JF, Guindon S, Lefort V, Lescot M, Claverie JM, Gascuel O (2008) Phylogeny.fr: robust phylogenetic analysis for the non-specialist. Nucleic Acids Res 36(Web Server issue):W465-W469. https://doi.org/10.1093/nar/gkn180.Epub 
Dolgin ES, Fe'Lix MA, Cutter AD (2008) Hakuna Nematoda: genetic and phenotypic diversity in African isolates of Caenorhabditis elegans and C. briggsae. Heredity 100(3):304-315. https://doi.org/10.1038/sj.hdy.6801079

Gaugler R (2002) Entomopathogenic nematology. CABI Publishing, Wallingford. https://doi.org/10.1079/9780851995670.0000

Isaac NJB, Mallet J, Mace GM (2004) Taxonomic inflation: its influence on acroecology and conservation. Trends Ecol. Evol. 19(9):464-469. https://doi. org/10.1016/j.tree.2004.06.004

Joyce SA, Burnell AM, Powers TO (1994) Characterization of Heterorhabditis isolates by PCR amplification of segments of mtDNA and rDNA genes. J Nematol 26:260-270

Kary NE, Niknam G, Griffin CT, Mohammadi SA, Moghaddam MA (2009) Survey of entomopathogenic nematodes of the families Steinernematidae and Heterorhabditidae (Nematoda: Rhabditida) in the north-west of Iran. Nematol. 11(1):107-116. https://doi.org/10.1163/156854108X398453

Kaya HK, Stock SP (1997) Techniques in insect nematology. In: Lacey LA (ed) Manual of techniques in insect pathology. Academic Press, London, pp 281324

Khashaba EHK, Moghaieb REA, El Abd Azim AM, Ibrahim SAM (2020) Isolation, identification of entomopathogenic nematodes, and preliminary study of their virulence against the great wax moth, Galleria mellonella L. (Lepidoptera: Pyralidae). Egypt J Biol Pest Control 30:55

Lax P, Dueñas JCR, Gardenal CN, Doucet ME (2007) Assessment of genetic variability in populations of Nacobbus aberrans (Thorne, 1935) Thorne and Allen, 1944 (Nematode: Pratylenchidae) from Argentina. Nematology. 9:261270

Laznik Z, Znidarcic D, Trdan S (2011) Control of Trialeurodes vaporariorum (Westwood) adults on glasshouse-grown cucumbers in four different growth substrates: an efficacy comparison of foliar application of Steinernema feltiae (Filipjev) and spraying with thiamethoxamn. Turk J Agric For. 35(631):640

Machkour-M'Rabet S, Henaut Y, Dor A, Pérez-Lachaud G (2009) ISSR (inter simple sequence repeats) as molecular markers to study genetic diversity in Tarantulas (Mygalomorphae). J Arachnol 37(Apr):10-14. https://doi.org/10.163 6/A08-27.1

Mehle N, Trdan S (2012) Traditional and modern methods for the identification of thrips (Thysanoptera) species. J Pest Sci 85(2):179-190. https://doi.org/10.1 007/s10340-012-0423-4

Mejia-Torres MC, Sáenz A (2013) Ecological characterization of the Colombian entomopathogenic nematode Heterorhabditis sp. SL0708. Braz J Biol 73(2): 239-243. https://doi.org/10.1590/S1519-69842013000200003

Nguyen KB, Hunt DJ, Mráček Z (2007) Steinernematidae: species description. In: Nguyen KB, Hunt DJ (eds) Entomopathogenic nematodes: systematics, phylogeny and bacterial symbionts. Nematology monographs and perspectives no. 5, Hunt D.J. and Perry R.N. serieseditors. Brill, Leiden, pp 121-609

Nour El-Deen AH (2018) Validation of DNA fingerprinting techniques in characterization of entomopathogenic nematodes. J Entomol Zool Stud 6(4): $226-231$

Reddy MP, Sarla N, Siddiq EA (2002) Inter simple sequence repeat (ISSR) polymorphism and its application in plant breeding. Euphytica 128(1):9-17. https://doi.org/10.1023/A:1020691618797

Singh SP, Yadav AK, Shachi V, Tripathi CPM (2015) Diversity analysis of entomopathogenic nematodes against Helicoverpa armigera (Hübner) from Tarai region of IGP, India. Curr Life Sci 1(1):15-23

Stock SP, Campbell JF, Nadler SA (2001) Phylogeny of Steinernema Travassos, 1927 (Cephalobina: Steinernematidae) inferred from ribosomal DNA sequences and morphological characters. J Parasitol 87(4):877-889. https://doi.org/10.2307/3285148

Valadas V, Laranjo M, Mota M, Oliveira S (2013) A survey of entomopathogenic nematode species in continental Portugal. J Helminthol:1-15. https://doi. org/10.1017/S0022149X13000217

Zhao GH, Li J, Zou FC, Mo XH, Yuan ZG, Lin RQ, Weng YB, Zhu XQ (2009) ISSR, an effective molecular approach for studying genetic variability among Schistosoma japonicum isolates from different provinces in mainland China. Infect Genet Evol 9(5):903-907. https://doi.org/10.1016/j.meegid.2009.06.006

\section{Publisher's Note}

Springer Nature remains neutral with regard to jurisdictional claims in published maps and institutional affiliations.

\section{Submit your manuscript to a SpringerOpen ${ }^{\circ}$ journal and benefit from:}

- Convenient online submission

- Rigorous peer review

- Open access: articles freely available online

High visibility within the field

- Retaining the copyright to your article

Submit your next manuscript at $\boldsymbol{\nabla}$ springeropen.com 